\title{
Immunophilin ligands in peripheral nerve regeneration
}

\author{
Y. Behram Kandemir, L. Sarikcioglu \\ Department of Anatomy, Akdeniz University Faculty of Medicine, Antalya, Turkey \\ [Received 12 August 2014; Accepted 25 October 2014]
}

\begin{abstract}
Immunophilins are a family of receptors for immunosuppressive drugs like cyclosporin A, FK506, rapamycin and their non-immunosuppressive analogues, which are collectively referred to as immunophilin ligands. The present study aimed to review neuroprotective and neuroregenerative actions of immunophilin ligands on peripheral nerve injuries. The special emphasis was given to well-known immunosuppressive drug FK506. Its historical background, administration routes, dosages, neuroregenerative, neuroprotective actions, therapeutic time window in administration, action mechanism and side effects of FK506 were reviewed. (Folia Morphol 2015; 74, 4: 407-413)
\end{abstract}

Key words: immunophilins, FK506, cyclosporin A, rapamycin, peripheral nerve

\section{INTRODUCTION}

Immunophilins are a family of receptors for immunosuppressive drugs like cyclosporin A, FK506, rapamycin and their non-immunosuppressive analogues, which are collectively referred to as "immunophilin ligands" [3]. In contrast to neurotrophins (e.g., nerve growth factor), immunophilin ligands readily cross the blood-brain barrier, being orally effective in a variety of animal models of ischaemia, traumatic injuries and human neurodegenerative disorders [27]. FK506 and rapamycin show their effects via binding to a class of immunophilin called FK506-binding proteins (FKBP), designated according to their molecular weight: FKBP12, 25, 52, etc. FKBP52 is also known as FKBP59 or heat shock protein 56 and is a component of steroid receptor complexes [2]. Cyclosporin A shows its effects via binding to cyclophilin [72].

\section{CYCLOSPORIN A}

Cyclosporin $A$ is a neutral lipophilic cyclic undecapeptide, of molecular weight 1202.6, obtained from the fermentation broth of two fungi, Trichoderma polyspo- rum and Cylindrocarpon lucidum [45]. Its immunosuppressive activity was first reported by Borel et al. [5] at Sandoz Laboratories in 1972. Discovery of the cyclosporin $\mathrm{A}$ has revolutionised transplantation medicine in which there is a need for immunosuppressive therapy.

Generally, cyclosporin A has similar immune-suppressing characteristics to FK506, but FK506 delivers a more potent effect with equal volumes of drug. Cyclosporin A binds to a class of immunophilins called cyclophilins [72]. Cyclophilin-cyclosporin A complex can associate with calcineurin [48]. Calcineurin (also known as PP-2B), is known as a calcium and calmodulin-dependent protein serine/threonine phosphatase. The role of calcineurin in T cell receptor signalling was identified as the common target for cyclosporin A and FK506 [71]. Calcineurin consists of two subunits, a catalytic subunit calcineurin $A$, and a regulatory subunit calcineurin $B$ [55].

\section{RAPAMYCIN}

Rapamycin is another immunosuppressant drug structurally related to FK506 and appears to act upon 
a similar step that exists in distinct signalling pathways associated with growth factor receptors [18]. Similarly, Myckatyn et al. [56] reported that animals treated with FK506 and rapamycin had significantly less immune cell proliferation within their severed nerve than control animals, with axon regeneration being superior in FK506 than rapamycin-treated animals.

Rapamycin has a structural similarity with FK506 but does not block cytokine transcription at the early stages of T-cell activation. Rapamycin inhibits proliferation of $T$ cells in response to growth-promoting cytokines like interleukin-2 at the G1- to S-phase progression [36]. FK506 and rapamycin show their effects via binding to a class of immunophilin called the FK506-binding protein-FKBP12 and the FKBP-rapamycin-associated protein [12]. Rapamycin binds to FKBP and the complex binds to rapamycin and FKBP-12 target [63]. FKBP-12 target affects protein translation by phosphorylating p70-S6 kinase, which phosphorylates the ribosomal S6 protein, and 4E-BP1, a repressor of protein translation initiation. Immunophilin levels are much higher in the brain than in immune tissues, and levels of FKBP12 increase in regenerating neurons in parallel with growth associated protein (GAP-43) [63].

\section{FK506}

\section{Historical background}

FK506 (its genetic name is Tacrolimus, Prograf ${ }^{\mathrm{TM}}$ ) was first discovered in 1984 by Fujisawa Pharmaceutical Company while screening for antibacterial activity of a multitude of compounds [43]. It was isolated from Streptomyces tsukabaensis, a bacterium found in the soil near Tsukuba, Japan [42, 43]. For this reason, the name of the drug is derived from the phrase of Tsukuba, the name of the mountain from which the soil sample was extracted; macrolide, its chemical class; and immune suppressant, its primary activity in humans [57].

\section{Action mechanism of FK506}

In experimental studies, it has been documented that FK506 enhances the rate of axonal regeneration after peripheral nerve injury $[29,30,39,76,77]$ and reduces post-occlusional disturbances of the central nervous system $[1,17,58,66]$. It would not be expected that an immunosuppressant drug (FK506) would alter axonal regeneration since Wallerian degeneration is not an immune-mediated event.
Gillon et al. [25] studied the ability of peripheral nerve allografts (from Dark-Agouti rats) to support regeneration of adult rat retinal ganglion cell axons in immunosuppressed host Lewis rats and found that systemic administration of the cyclosporin A or FK506 significantly reduced cellular infiltration into peripheral nerve allografts and resulted in more extensive axonal regeneration [25]. Fansa et al. [20] reported a decrease in myelin debris in autologous nerve grafts by administration of $0.6 \mathrm{mg} / \mathrm{kg}$ FK506. Furthermore, even if a reduction in macrophage infiltration occurs following FK506 administration [9], such an alteration would be expected to impair nerve regeneration by delaying the removal of debris from the distal stump $[11,49]$.

It is well documented that FK506 activity is mediated by FKBP (FK506 binding protein). Lyons et al. [51] reported significant increase in FKBP12 levels in facial or sciatic nerve nuclei after crush injury. Synder and Sabatini [67] also showed levels for FKBP-12 mRNA increased significantly in motor neurons following peripheral nerve axotomy. Presence of high levels of FKBP corresponds with the presence of high levels calcineurin $[51,67]$. The influence of FK506 on axon regeneration is predominantly through the binding to FKBP-12, which activates GAP-43 and the transforming growth factor (TGF $\beta 1$ ) pathway [21, 31]. The FK506-FKBP complex further binds to calcineurin, preventing the dephosphorylation of the nuclear factor of activated T cells and blocking the cascade of cytokine gene transcription. Calcineurin has the ability to dephosphorylate a broad range of proteins [54]. One of the major targets for calcineurin in neurons is GAP-43. Both GAP-43 and neuronal phosphates are concentrated in growth cones of the proximal stump of the lesioned nerve, where they are believed to play an important role in nerve regeneration [64]. In an elegant study, Gold et al. [32] demonstrated that non-FKBP-12 ligand (V-13.670) accelerates functional recovery and nerve regeneration in the rat sciatic nerve crush model.

\section{Neuroregenerative actions of FK506}

FK506 is the first agent in which systemic exposures have been demonstrated to increase axonal regeneration rate [30]. Continuous infusion of insulin like growth factor I, cyclosporin A, adenocorticotropic hormone (ACTH) analogue Org 2766 directly to the lesion site have been shown to increase axonal regeneration $[19,26,40]$. Although systemic administration of the ACTH analogue Org 2766 increase 
recovery of function, rate determinations have not been reported $[15,68]$ Additionally, FK506 is not structurally related to any known growth-promoting factor and it is therefore likely to accelerate regeneration via a novel mechanism [30].

Despite documented neurotoxicity with high dosages, both cyclosporin A and FK506 have had no deleterious effect on nerve regeneration of nerve allografts. Gold et al. [30] noted an increased rate of nerve regeneration after FK506 treatment in axonotmesis model of the sciatic nerve. Additionally, their group also studied the efficacy of delayed or discontinuous FK506 administration on axonal regeneration and found that both delayed and discontinuous administration were less effective than continuous administration [29].

FK506 treatment has been document in facial [16], sciatic [30, 64, 73], vagus [33] and obturator nerve models [79]. FK506 enhances collateral sprouting of peripheral nerve fibres [73]. Sulaiman et al. [70] studied whether FK506 is effective after chronic nerve injuries (chronic axotomy, chronic Schwann cell denervation). For chronic axotomy, injured tibial nerve was sutured to a freshly cut common peroneal nerve after 2 months delay. For chronic denervation, injured distal common peroneal nerve was sutured to a freshly cut tibial nerve after 2 months delay. In contrast to effect of FK506 in chronic axotomy model, FK506 did not improve the reduced capacity of Schwann cells to support axonal regeneration in chronic denervation model. Sulaiman et al. [70] suggest that FK506 acts directly on the neuron (as opposed to the denervated distal nerve stump) to accelerate and promote axonal regeneration of neurons whose regenerative capacity is significantly reduced by chronic axotomy.

Scar formation is another important issue for peripheral nerve regeneration. Traditionally, surgeons attempt to control collagen scar formation by close approximation of corresponding fascicles of the proximal to distal stumps [23, 37]. Excessive collagen formation can create a mechanical barrier to axonal regeneration, and the resulting scar formation can hinder axonal regrowth [41, 44, 53]. Que et al. [62] studied the effect of FK506 in reducing scar formation by inducing fibroblast apoptosis after sciatic nerve injury in rats. They suggest that FK506-induced fibroblast apoptosis contributes to the suppression of fibroblast proliferation and then results in the reduction of scar formation in injured nerve, and that c-Jun N-terminal kinase (JNK) and extracellular-signal- -regulated kinase (ERK) are involved in FK506-induced fibroblast apoptosis.

Despite effect of FK506 on traumatic nerve injuries has been documented in literature, few studies reported by our group on vascular injuries of the peripheral nerve. In a previous study [75], we reported a beneficial effect of the FK506 on subperineurial degeneration and demyelination of the nerve fibres in the watershed zones of the sciatic nerve after stripping of the epineurial vessels. Earlier studies suggested that sufficient oxygen could diffuse into peripheral nerve from its environment to delay ischaemic conduction failure and to prevent fibre degeneration in ischaemic nerves $[17,29,30]$. In another study [35] we also demonstrated that reduction of the per cent of watershed areas in the subperineurial area was not affected from FK506 administration. This result supports the evidence of the neuroprotective effects of the FK506. This effect may be modulated by reducing the scar formation as reported recently by Que et al. [62] or by changing the blood flow through collaterals of the vasa nervorum.

\section{Neuroprotective actions of FK506}

Knowledge on mechanism of action of immunophilin ligands may shed light on neuroprotective actions in neurons. In several animal models simulating Parkinson's disease, dementia and surgical damage, it has been reported that immunophilin ligands induces sprouting by acting as neurotrophic agents and preventing nerve damage [61]. FKBP12 might be protective due to its action of binding to and stabilising inositol trisphosphate (IP3) and ryanodine calcium channels $[8,10]$, since an increase in intracellular calcium levels has been linked to neuronal death [2].

Trauma-induced neurological losses are the main challenge for physicians since trauma leads to the death of some perikarya located in the central nervous system. Attempts to reduce the secondary changes in the neurons will reduce the functional loss of the peripheral nerve. Thus, the administration of the immunosuppressants in a therapeutic time after trauma will result to maintaining the neurons viability and allowing to regenerate and re-establish connections to their original target [72]. Although protection against focal cerebral ischaemia has been reported, even when FK506 administered even up to $60 \mathrm{~min}$ postocclusion of the middle cerebral artery $[1,6,58,80]$, neurite outgrowth rat dorsal root ganglia has been 
documented in the literature [50]. Its neuroprotective effect on primary cortical cultures has also been demonstrated [14].

\section{Therapeutic time window in administration of FK506}

In the clinical routine an immediate reconstruction of the lesioned nerve is seldom possible since clinicians tend to wait prior to making their diagnosis and plans for treatment [72]. In contrast to typical animal models for nerve regeneration studies, mostly there is a certain denervation time of the affected nerve between lesion and reconstruction. Therefore, it is important to know the optimal therapeutic time window of effectiveness of FK506 following nerve trauma. Focal ischaemia in which FK506 effectiveness is dependent on its dose and therapeutic time window is well studied in experimental studies $[1,24]$.

Chunasuwankul et al. [13] demonstrated that prolonging FK506 treatment (from 2 months to 3 months treatment) following an acute nerve cut did not increase the recovery of function. Contrary to this effect, when FK506 is administered 2 months after nerve transection rate of axon regeneration was doubled. This result may be considered in line of when it is administered to an acutely damaged peripheral nerve [70]. It has been reported that $5 \mathrm{mg} / \mathrm{kg} /$ day subcutaneous administration of FK506 is equally as effective when given discontinuously, starting immediately following nerve section (days 0-8 and 10-17), or with a delay (days 9-17), with continuous administration starting immediately being most effective [76]. Brenner et al. [7] studied delay administration of FK506 and reported the greatest influence of FK506 when it was administrated immediately following the lesion. Delaying for the nerve repair and for the administration of FK506 (even by 7 days), or immediate surgery with delayed administration of FK506 leaded to less extensive axon regeneration and fewer motor neurons extending axons [7]. Okajima et al. [60] reported that short-term administration (12 weeks) of FK506 was sufficient to lead to good nerve regeneration in peripheral nerve allografts.

\section{Administration routes and dosages of FK506}

A broad range of dosages $(0.3-10 \mathrm{mg} / \mathrm{kg})$ of the FK506 for peripheral nerve regeneration has been reported in the literature $[4,20,22,30,31,39,46$, $52,77]$. It can be thought that the wide range of these dosages may be due to the administration route of the FK506. It has been reported that the most effective neuroprotective dose of FK506 is $1 \mathrm{mg} / \mathrm{kg}$ [24, $58,80]$, which corresponds to immunosuppressive dose in humans [66].

Wang et al. [77] reported a dose dependent fashion of FK506 treatment on nerve regeneration. They studied the effect of 2, 5, and $10 \mathrm{mg} / \mathrm{kg}$ doses of FK506 on recovery of function. They reported that recovery was maximally accelerated with daily administration of $5 \mathrm{mg} / \mathrm{kg}$ dose. $10 \mathrm{mg} / \mathrm{kg}$ dose of FK506 was observed to be less effective. Fansa et al. [20] also studied the effect of 2 dosages $(0.3,0.6 \mathrm{mg} / \mathrm{kg}$ s.c.) of FK506 on peripheral nerve regeneration following nerve grafting and reported significantly higher axon count in both groups administrated 2 dosages of the FK506. But there is no consensus about the optimal dose of the FK506 to achieve the best regeneration rate. Additionally, the dosages reported in the literature are seemed to be very high dosages [64].

Although subcutaneous, oral, intramuscular FK506 administrations have been frequently reported, to our knowledge, there is only 1 study investigating the effect of intrathecal FK506 administration on axonal regeneration [64]. The lowest dose reported in the literature was studied by our research group. We administered $0.05 \mathrm{mg} / \mathrm{kg} /$ day dose of FK506 intrathecally and studied the beneficial effect of FK506 after sciatic nerve injury. This beneficial effect was confirmed by myelin loss, myelin degeneration, functional and sensory function. Since liver transplant patients receive approximately same dose, we used this dose to obtain lesser immunosuppression, neurotoxicity. We think that intrathecal administration of the FK506 should be kept in mind to decrease side effects of the FK506 during treatment of the nerve injury.

One of the other administration routes is loading the FK506 to semi-permeable wall of chitosan guide $(647 \mu \mathrm{g} / \mathrm{g})$. FK506 was dispersed in chitosan guide wall during fabrication of the chitosan guide. It was reported that FK506 releasing from biodegradable chitosan guide provided better nerve regenerative response than the guide with no FK506 [47].

\section{Side effects of FK506}

In addition to its ability to suppress the immune system cells (T-cell activity) FK506 has a number of non-immune effects $[17,34,59,65,74,78]$. Although an increased rate of axonal regeneration has been noted in various rodent models [30,51], neurological and other side effects, such as metabolic, cosmetic, 
and neuropsychiatric complications resulted from immunosuppressant therapy with FK506 have also been reported in the central and peripheral nervous system [72]. New immunosuppressive agents, such as mycophenolate mofetil and sirolimus, have similar side effects. The neuroregenerative property of the immunophilin ligands does not involve calcineurin inhibition (it is essential for immunosuppression). This pathway is important since most of the limiting side effects produced by these drugs arise via calcineurin inhibition [27].

One of the more serious complications of FK506 treatment in animal models is the development of diabetes mellitus [72]. However, up to 240 days administration of FK506, the increased glucose levels are not chronic, and eventually return to normal level, making FK506 treatment effects on glycaemia only a time-related side effect [60]. One of the mechanism at which FK506 appears to induce neurological side effects is production of reactive oxygen species and a decreased the levels of antioxidant enzymes [38]. It is proposed to inhibit these side effects by co-administration of antioxidants with FK506 administration. Although there are some choices to decrease the side effects cyclosporine and FK506-based immunosuppressive treatments induce additional side effects, such as metabolic, cosmetic, and neuropsychiatric, which still raise concern about their use [69].

In a previous study we administered the FK506 intrathecally $(0.05 \mathrm{mg} / \mathrm{kg} /$ day $)$, the lowest dose reported in the literature for treatment of the sciatic nerve injury, and found no side effects in the FK506-treated animals. Thus, side effects may be diminished by using alternative administration route.

\section{NONIMMUNOSUPPRESSANT FK506 ANALOGS}

Three non-immunosuppressant FK506 analogues such as V-13.450, V-13.629, and V-13.670 have also been described by Gold et al. [28]. They are equipotent to FKBP-12 ligands (FK506, V-10.367, and $\mathrm{V}$-13.449) for increasing neurite elongation in $\mathrm{SH}-\mathrm{SY} 5 \mathrm{Y}$ cells in hippocampal neurons from FKBP-12 knockout mice [28].

\section{CONCLUSIONS AND FUTURE PERSPECTIVE}

Novel non-immunosuppressant ligands for FKBPs seemed an alternative for returning the recovery of function after peripheral nerve injury. Although FK506 is used extensively for its immunosuppressive actions because of its limited number of side effects, especially when used in adults, new compounds must be further studied for their potential benefits in enhancing axon regeneration and neurological recovery following diseases of both peripheral and central nervous system.

\section{ACKNOWLEDGEMENTS}

The authors thank Akdeniz University Project Management Unit (Akdeniz University Research Fund) for their financial support.

\section{REFERENCES}

1. Arii T, Kamiya T, Arii K, Ueda M, Nito C, Katsura KI, Katayama Y (2001) Neuroprotective effect of immunosuppressant FK506 in transient focal ischemia in rat: therapeutic time window for FK506 in transient focal ischemia. Neurol Res, 23: 755-760.

2. Avramut $M$, Achim CL (2002) Immunophilins and their ligands: insights into survival and growth of human neurons. Physiol Behav, 77: 463-468.

3. Avramut $\mathrm{M}$, Achim CL (2003) Immunophilins in nervous system degeneration and regeneration. Curr Top Med Chem, 3: 1376-1382.

4. Bavetta S, Hamlyn PJ, Burnstock G, Lieberman AR, Anderson PN (1999) The effects of FK506 on dorsal column axons following spinal cord injury in adult rats: neuroprotection and local regeneration. Exp Neurol, 158: 382-393.

5. Borel JF, Feurer C, Gubler HU, Stahelin H (1976) Biological effects of cyclosporin A: a new antilymphocytic agent. Agents Actions, 6: 468-475.

6. Brecht $S$, Waetzig V, Hidding U, Hanisch UK, Walther M, Herdegen T, Neiss WF (2009) FK506 protects against various immune responses and secondary degeneration following cerebral ischemia. Anat Rec (Hoboken), 292: 1993-2001.

7. Brenner MJ, Fox IK, Kawamura DH, Yu VM, Lowe JB, 3rd, Hunter DA, Mackinnon SE (2004) Delayed nerve repair is associated with diminished neuroenhancement by FK506. Laryngoscope, 114: 570-576.

8. Brillantes $A B$, Ondrias K, Scott A, Kobrinsky E, Ondriasova E, Moschella MC, Jayaraman T, Landers M, Ehrlich BE, Marks AR (1994) Stabilization of calcium release channel (ryanodine receptor) function by FK506-binding protein. Cell, 77: 513-523.

9. Bruck W, Friede RL (1990) Anti-macrophage CR3 antibody blocks myelin phagocytosis by macrophages in vitro. Acta Neuropathol, 80: 415-418.

10. Cameron AM, Steiner JP, Roskams AJ, Ali SM, Ronnett GV, Snyder SH (1995) Calcineurin associated with the inositol 1,4,5-trisphosphate receptor-FKBP12 complex modulates Ca2+ flux. Cell, 83: 463-472.

11. Chen S, Bisby MA (1993) Impaired motor axon regeneration in the C57BL/Ola mouse. J Comp Neurol, 333: 449-454.

12. Choi J, Chen J, Schreiber SL, Clardy J (1996) Structure of the FKBP12-rapamycin complex interacting with the binding domain of human FRAP. Science, 273: 239-242. 
13. Chunasuwankul R, Ayrout C, Dereli Z, Gal A, Lanzetta M, Owen E (2002) Low dose discontinued FK506 treatment enhances peripheral nerve regeneration. Int Surg, 87: 274-278.

14. Dawson TM, Steiner JP, Dawson VL, Dinerman JL, UhI GR, Snyder SH (1993) Immunosuppressant FK506 enhances phosphorylation of nitric oxide synthase and protects against glutamate neurotoxicity. Proc Natl Acad Sci USA, 90: 9808-9812.

15. De Koning P, Gispen WH (1987) Org.2766 improves functional and electrophysiological aspects of regenerating sciatic nerve in the rat. Peptides, 8: 415-422.

16. Diaz LM, Steele MH, Guerra AB, Aubert FE, Sloop GD, Diaz $H A$, Metzinger RC, Blake DB, Delaune $C L$, Metzinger SE (2004) The role of topically administered FK506 (tacrolimus) at the time of facial nerve repair using entubulation neurorrhaphy in a rabbit model. Ann Plast Surg, 52: 407-413.

17. Drake M, Friberg H, Boris-Moller F, Sakata K, Wieloch $T$ (1996) The immunosuppressant FK506 ameliorates ischaemic damage in the rat brain. Acta Physiol Scand, 158: 155-159.

18. Dumont FJ, Melino MR, Staruch MJ, Koprak SL, Fischer PA, Sigal NH (1990) The immunosuppressive macrolides FK506 and rapamycin act as reciprocal antagonists in murine T cells. J Immunol, 144: 1418-1424.

19. Ekstrom AR, Kanje M, Skottner A (1989) Nerve regeneration and serum levels of insulin-like growth factor-I in rats with streptozotocin-induced insulin deficiency. Brain Res, 496: 141-147.

20. Fansa H, Keilhoff G, Altmann S, Plogmeier K, Wolf G, Schneider W (1999) The effect of the immunosuppressant FK 506 on peripheral nerve regeneration following nerve grafting. J Hand Surg Br, 24: 38-42.

21. Fansa H, Keilhoff G, Horn T, Altmann S, Wolf G, Schneider W (1999) Stimulation des Wachstums Schwannscher Zellen und der axonalen Regeneration peripherer Nerven durch das Immunsuppressivum FK 506. Handchir Mikrochir Plast Chir, 31: 323-329; discussion 330-322.

22. Feng FY, Ogden MA, Myckatyn TM, Grand AG, Jensen JN, Hunter DA, Mackinnon SE (2001) FK506 rescues peripheral nerve allografts in acute rejection. J Neurotrauma, 18: 217-229.

23. Fischer DW, Beggs JL, Kenshalo DL, Jr., Shetter AG (1985) Comparative study of microepineurial anastomoses with the use of $\mathrm{CO} 2$ laser and suture techniques in rat sciatic nerves: Part 1. Surgical technique, nerve action potentials, and morphological studies. Neurosurgery, 17: 300-308.

24. Furuichi Y, Katsuta K, Maeda M, Ueyama N, Moriguchi A, Matsuoka N, Goto T, Yanagihara T (2003) Neuroprotective action of tacrolimus (FK506) in focal and global cerebral ischemia in rodents: dose dependency, therapeutic time window and long-term efficacy. Brain Res, 965: 137-145.

25. Gillon RS, Cui Q, Dunlop SA, Harvey AR (2003) Effects of immunosuppression on regrowth of adult rat retinal ganglion cell axons into peripheral nerve allografts. J Neurosci Res, 74: 524-532.

26. Glazner GW, Lupien S, Miller JA, Ishii DN (1993) Insulin-like growth factor II increases the rate of sciatic nerve regeneration in rats. Neuroscience, 54: 791-797.

27. Gold BG (2000) Neuroimmunophilin ligands: evaluation of their therapeutic potential for the treatment of neurological disorders. Expert Opin Investig Drugs, 9: 2331-2342.

28. Gold BG, Armistead DM, Wang MS (2005) Non-FK506-binding protein-12 neuroimmunophilin ligands increase neurite elongation and accelerate nerve regeneration. J Neurosci Res, 80: 56-65.
29. Gold BG, Gordon HS, Wang MS (1999) Efficacy of delayed or discontinuous FK506 administrations on nerve regeneration in the rat sciatic nerve crush model: lack of evidence for a conditioning lesion-like effect. Neurosci Lett, 267: 33-36.

30. Gold BG, Katoh K, Storm-Dickerson T (1995) The immunosuppressant FK506 increases the rate of axonal regeneration in rat sciatic nerve. J Neurosci, 15: 7509-7516.

31. Gold BG, Yew JY, Zeleny-Pooley M (1998) The immunosuppressant FK506 increases GAP-43 mRNA levels in axotomized sensory neurons. Neurosci Lett, 241: 25-28.

32. Gold BG, Zeleny-Pooley M, Chaturvedi P, Wang MS (1998) Oral administration of a nonimmunosuppressant FKBP-12 ligand speeds nerve regeneration. Neuroreport, 9: 553-558.

33. Gorphe P, Guerout N, Birchall M, Terenghi G, Marie JP (2012) Tacrolimus enhances the recovery of normal laryngeal muscle fibre distribution after reinnervation. J Laryngol Otol, 126: 1155-1158.

34. Heitman J, Koller A, Kunz J, Henriquez R, SchmidtA, Movva NR, Hall MN (1993) The immunosuppressant FK506 inhibits amino acid import in Saccharomyces cerevisiae. Mol Cell Biol, 13: 5010-5019.

35. Hizay A, Demirel BM, Gokhan G, Sarikcioglu L, Demir N (2011) Does FK506 reduce the size of the watershed area after vascular injury of the sciatic nerve? Rom J Morphol Embryol, 52: 1077-1080.

36. Ho S, Clipstone N, Timmermann L, Northrop J, Graef I, Fiorentino D, Nourse J, Crabtree GR (1996) The mechanism of action of cyclosporin A and FK506. Clin Immunol Immunopathol, 80: S40-45.

37. Holmes W, Young JZ (1942) Nerve regeneration after immediate and delayed suture. J Anat, 77: 63-96.

38. Jin KB, Hwang EA, Han SY, Park SB, Kim HC, Ha EY, Suh SI, Mun KC (2008) Effects of tacrolimus on antioxidant status and oxidative stress in glioma cells. Transplant Proc, 40: 2740-2741.

39. Jost SC, Doolabh VB, Mackinnon SE, Lee M, Hunter D (2000) Acceleration of peripheral nerve regeneration following FK506 administration. Restor Neurol Neurosci, 17: 39-44.

40. Kanje M, Skottner A, Sjoberg J, Lundborg G (1989) Insulin-like growth factor I (IGF-I) stimulates regeneration of the rat sciatic nerve. Brain Res, 486: 396-398.

41. Kaplan S, Piskin A, Ayyildiz M, Aktas A, Koksal B, Ulkay MB, Turkmen AP, Bakan F, Geuna S (2011) The effect of melatonin and platelet gel on sciatic nerve repair: an electrophysiological and stereological study. Microsurgery, 31: 306-313.

42. Kino $T$, Hatanaka $H$, Hashimoto $M$, Nishiyama $M$, Goto $T$, Okuhara M, Kohsaka M, Aoki H, Imanaka H (1987) FK-506, a novel immunosuppressant isolated from a Streptomyces. I. Fermentation, isolation, and physico-chemical and biological characteristics. J Antibiot (Tokyo), 40: 1249-1255.

43. Kino T, Hatanaka H, Miyata S, Inamura N, Nishiyama M, Yajima T, Goto T, Okuhara M, Kohsaka M, Aoki H, Imanaka H (1987) FK-506, a novel immunosuppressant isolated from a Streptomyces. II. Immunosuppressive effect of FK-506 in vitro. J Antibiot (Tokyo), 40: 1256-1265.

44. Lane JM, Bora FW, Jr., Pleasure D (1978) Neuroma scar formation in rats following peripheral nerve transection. J Bone Joint Surg Am, 60: 197-203.

45. Laupacis A, Keown PA, Ulan RA, McKenzie N, Stiller CR (1982) Cyclosporin A: a powerful immunosuppressant. Can Med Assoc J, 126: 1041-1046. 
46. Lee M, Doolabh VB, Mackinnon SE, Jost S (2000) FK506 promotes functional recovery in crushed rat sciatic nerve. Muscle Nerve, 23: 633-640.

47. Li X, Wang W, Wei G, Wang G, Zhang W, Ma X (2010) Immunophilin FK506 loaded in chitosan guide promotes peripheral nerve regeneration. Biotechnol Lett, 32: 1333-1337.

48. Liu J, Farmer JD, Jr., Lane WS, Friedman J, Weissman I, Schreiber SL (1991) Calcineurin is a common target of cyclophilin-cyclosporin A and FKBP-FK506 complexes. Cell, 66: 807-815.

49. Ludwin SK, Bisby MA (1992) Delayed wallerian degeneration in the central nervous system of Ola mice: an ultrastructural study. J Neurol Sci, 109: 140-147.

50. Lyons WE, George EB, Dawson TM, Steiner JP, Snyder SH (1994) Immunosuppressant FK506 promotes neurite outgrowth in cultures of PC12 cells and sensory ganglia. Proc Natl Acad Sci USA, 91: 3191-3195.

51. Lyons WE, Steiner JP, Snyder SH, Dawson TM (1995) Neuronal regeneration enhances the expression of the immunophilin FKBP- 12. J Neurosci, 15: 2985-2994.

52. Madsen JR, MacDonald P, Irwin N, Goldberg DE, Yao GL, Meiri KF, Rimm IJ, Stieg PE, Benowitz LI (1998) Tacrolimus (FK506) increases neuronal expression of GAP-43 and improves functional recovery after spinal cord injury in rats. Exp Neurol, 154: 673-683.

53. Menovsky T, Beek JF (2001) Laser, fibrin glue, or suture repair of peripheral nerves: a comparative functional, histological, and morphometric study in the rat sciatic nerve. J Neurosurg, 95: 694-699.

54. Morioka M, Hamada J, Ushio Y, Miyamoto E (1999) Potential role of calcineurin for brain ischemia and traumatic injury. Prog Neurobiol, 58: 1-30.

55. Mukai H, Kuno T, Chang CD, Lane B, Luly JR, Tanaka C (1993) FKBP12-FK506 complex inhibits phosphatase activity of two mammalian isoforms of calcineurin irrespective of their substrates or activation mechanisms. J Biochem (Tokyo), 113: 292-298.

56. Myckatyn TM, Ellis RA, Grand AG, Sen SK, Lowe JB, 3rd, Hunter DA, Mackinnon SE (2002) The effects of rapamycin in murine peripheral nerve isografts and allografts. Plast Reconstr Surg, 109: 2405-2417.

57. Nghiem P, Pearson G, Langley RG (2002) Tacrolimus and pimecrolimus: from clever prokaryotes to inhibiting calcineurin and treating atopic dermatitis. J Am Acad Dermatol, 46: 228-241.

58. Noto T, Ishiye M, Furuich Y, Keida Y, Katsuta K, Moriguchi A, Matsuoka N, Aramori I, Goto T, Yanagihara T (2004) Neuroprotective effect of tacrolimus (FK506) on ischemic brain damage following permanent focal cerebral ischemia in the rat. Brain Res Mol Brain Res, 128: 30-38.

59. Ohnishi $H$, Muto $Y$, Maeda T, Hayashi T, Nagaki M, Yamada T, Shimazaki M, Yamada Y, Sugihara J, Moriwaki H (1993) Natural killer cell may impair liver regeneration in fulminant hepatic failure. Gastroenterol Jpn, 28: 40-44.

60. Okajima S, Hojo T, Tamai K, Takai S, Hirasawa Y (2002) Histological and electrophysiological analysis of the peripheral nerve allografts using an immunosuppressive agent. Microsc Res Tech, 58: 52-58.

61. Park HJ, Rosado JA, Redondo PC, Cho YS (2011) Immunophilin dysfunction and neuropathology. Curr Med Chem, 18: 5398-5407.

62. Que J, Cao Q, Sui T, Du S, Kong D, Cao X (2013) Effect of FK506 in reducing scar formation by inducing fibroblast apoptosis after sciatic nerve injury in rats. Cell Death Dis, 4: e526.

63. Sabatini DM, Lai MM, Snyder SH (1997) Neural roles of immunophilins and their ligands. Mol Neurobiol, 15: 223-239.

64. Sarikcioglu L, Duygulu E, Aydin H, Gurer El, Ozkan O, Tuzuner S (2006) Effects of intrathecal administration of FK506 after sciatic nerve crush injury. J Reconstr Microsurg, 22: 649-654.

65. Schmidt A, Hall MN, Koller A (1994) Two FK506 resistance-conferring genes in Saccharomyces cerevisiae, TAT1 and TAT2, encode amino acid permeases mediating tyrosine and tryptophan uptake. Mol Cell Biol, 14: 6597-6606.

66. Sharkey J, Butcher SP (1994) Immunophilins mediate the neuroprotective effects of FK506 in focal cerebral ischaemia. Nature, 371: 336-339.

67. Snyder SH, Sabatini DM (1995) Immunophilins and the nervous system. Nat Med, 1: 32-37.

68. Sporel-Ozakat RE, Edwards PM, Van der Hoop RG, Gispen WH (1990) An ACTH-(4-9) analogue, Org 2766, improves recovery from acrylamide neuropathy in rats. Eur J Pharmacol, 186: 181-187.

69. Srinivas TR, Meier-Kriesche HU (2008) Minimizing immunosuppression, an alternative approach to reducing side effects: objectives and interim result. Clin J Am Soc Nephrol, 3 (suppl. 2): S101-S116.

70. Sulaiman OA, Voda J, Gold BG, Gordon T (2002) FK506 increases peripheral nerve regeneration after chronic axotomy but not after chronic schwann cell denervation. Exp Neurol, 175: 127-137.

71. Sun L, Youn HD, Loh C, Stolow M, He W, Liu JO (1998) Cabin 1, a negative regulator for calcineurin signaling in T lymphocytes. Immunity, 8: 703-711.

72. Toll EC, Seifalian AM, Birchall MA (2011) The role of immunophilin ligands in nerve regeneration. Regen Med, 6: 635-652.

73. Udina E, Ceballos D, Gold BG, Navarro X (2003) FK506 enhances reinnervation by regeneration and by collateral sprouting of peripheral nerve fibers. Exp Neurol, 183: 220-231.

74. Ueki M, Yasunami Y, Ina K, Ryu S, Funakoshi A, Kamei T, Ikeda S (1993) Diabetogenic effects of FK506 on renal subcapsular islet isografts in rat. Diabetes Res Clin Pract, 20: 11-19.

75. Utuk A, Sarikcioglu L, Demirel BM, Demir N (2009) The immunosuppressive agent FK506 prevents subperineurial degeneration and demyelination on ultrastructural and functional analysis. Curr Neurovasc Res, 6: 252-258.

76. Wang MS, Gold BG (1999) FK506 increases the regeneration of spinal cord axons in a predegenerated peripheral nerve autograft. J Spinal Cord Med, 22: 287-296.

77. Wang MS, Zeleny-Pooley M, Gold BG (1997) Comparative dose-dependence study of FK506 and cyclosporin A on the rate of axonal regeneration in the rat sciatic nerve. J Pharmacol Exp Ther, 282: 1084-1093.

78. Yamamoto S, Kato R (1994) Hair growth-stimulating effects of cyclosporin A and FK506, potent immunosuppressants. J Dermatol Sci, 7 (suppl.): S47-S54.

79. Yildirim FB, Sarikcioglu L, Ozsoy U, Demir N, Demirtop A, Ucar Y (2008) Effect of FK506 administration after obturator nerve injury: a functional and ultrastructural study. Acta Neurobiol Exp, 68: 477-483.

80. Zawadzka M, Kaminska B (2005) A novel mechanism of FK506-mediated neuroprotection: downregulation of cytokine expression in glial cells. Glia, 49: 36-51. 